\title{
ANALISIS USAHA DAN NILAI TAMBAH VCO DI KECAMATAN ENOK
}

\author{
Nina Sawitri \\ Program Studi Agribisnis Fakultas Pertanian UNISI \\ Email: ninasawitri@gmail.com
}

\begin{abstract}
ABSTRAK
Salah satu usaha agroindustri berbahan baku kelapa yang berkembang di Kecamatan Enok adalah VCO (Virgin Coconut Oil). VCO mempunyai nilai tambah yang besar karena dapat digunakan sebagai bahan baku berbagai produk. Tujuan penelitian ini adalah untuk mengetahui besarnya keuntungan usaha pengolahan VCO, efisiensi usaha pengolahan VCO dan besarnya nilai tambah usaha pengolahan VCO di Kecamatan Enok. Metode analsis data yang digunakan adalah analisis biaya, penerimaan, keuntungan dan efisiensi. Nilai tambah dihitung dengan metode Hayami. Hasil penelitian menunjukkan bahwa penerimaan dari usaha pengolahan VCO di Kecamatan Enok adalah sebesar Rp. $120.000,00$ per produksi. Total biaya yang harus dikeluarkan untuk satu kali produksi sebesar Rp.51.480,00, sehingga keuntungan usaha adalah Rp. 68.520,00 per produksi. Efisiensi usaha sebesar 2,33. Dari hasil ini usaha pengolahan VCO layak untuk diusahakan. Nilai tambah yang diperoleh dari pengolahan $1 \mathrm{~kg}$ bahan baku kelapa adalah Rp. 3.500,00. Rasio nilai tambah yang diperoleh adalah sebesar 20,83 \%. Keuntungan dari pengolahan VCO adalah sebesar Rp.500 per kg dengan tingkat keuntungan 14,29\%.
\end{abstract}

Kata Kunci: VCO, penerimaan, keuntungan, efisiensi, nilai tambah

\begin{abstract}
One of the agroindustry businesses made from coconut that develops in Enok District is VCO (Virgin Coconut Oil). VCO has great added value because it can be used as raw material for various products. The aims of this study was to determine the benefits of the VCO processing business, the efficiency of the VCO processing business and the added value of the VCO processing business in Enok District. The method used are the analysis of costs, revenues, profits and efficiency. Added value is calculated by the Hayami method. The results showed that the revenue from the VCO processing business in Enok District was Rp. 120.000,00 per production. The total cost for one time production is Rp.51.480,00, so the profit is Rp. 68.520,00 per production. Business efficiency of 2,33. From these results the VCO processing business is worth the effort. The added value obtained from processing $1 \mathrm{~kg}$ of coconut raw material is Rp. 3,500.00. The ratio of added value obtained is $20.83 \%$. The advantage of VCO processing is Rp.500 per kg with a profit rate of $14.29 \%$.
\end{abstract}

Keywords: VCO, revenue, profit, efficiency, added value 


\section{PENDAhuluan}

Salah satu usaha agroindustri yang memiliki prospek sangat bagus sehingga perlu mendapat perhatian untuk dikembangkan adalah agroindustri berbasis kelapa. Pengembangan agroindustri kelapa di Kabupaten Indragiri Hilir memiliki prospek yang menguntungkan karena ditunjang dengan ketersedian bahan baku yang banyak. Luas areal perkebunan kelapa di Kabupaten Indragiri Hilir adalah 440.525 hektar (BPS Provinsi Riau, 2013). Hal ini menyebabkan berbagai usaha pengolahan kelapa di Kabupaten Indragiri Hilir telah banyak diusahakan oleh masyarakat dalam bentuk usaha industri rumahtangga, seperti agroindustri minyak goreng, $\mathrm{VCO}$, gula kelapa, arang tempurung dan kopra (Dinas Koperasi dan UKM Kabupaten Inhil, 2017).

Kecamatan Enok adalah salah satu daerah Di Kabupaten Indragiri Hilir yang memiliki areal perkebunan kelapa yang cukup luas. Ketersediaan bahan baku yang cukup membuat usaha pengolahan kelapa di daerah ini cukup berkembang. Salah satu usaha pengolahan kelapa yang dilakukan oleh petani di daerah ini adalah pengolahan VCO. VCO adalah kelapa dara murni (Virgin Coconut Oil/VCO) yang harganya bisa mencapai tiga sampai empat kali minyak kelapa biasa. VCO mempunyai nilai tambah yang besar karena dapat digunakan sebagai bahan baku berbagai produk seperti kosmetik, sabun, makanan dan obat-obatan (Hartanti dan Mulyani, 2009).

Produk VCO yang dihasilkan di Kecamatan Enok umumnya dipasarkan hingga keluar daerah. Permintaan VCO yang tinggi menyebabkan usaha ini terus mengalami perkembangan. Selain itu, harga VCO yang cukup tinggi juga membuat usaha ini tetap diminati oleh petani. Di pasaran VCO dijual dengan harga bervariasi antara Rp. 35.000 sampai dengan Rp. 50.000 per $350 \mathrm{ml}$ tergantung kandungan asam lauratnya (Hartanti dan Mulyani, 2009).
Usaha pengolahan VCO menjadi salah satu alternatif usaha yang dilakukan petani karena harga buah kelapa di pasaran yang tidak stabil. Harga kelapa sangat fluktuatif bahkan cenderung rendah. Adanya usaha pembuatan VCO, diharapkan dapat memberikan solusi bagi pemasaran buah kelapa. Sehubungan dengan permasalahan tersebut maka perlu dicari solusi untuk mengkaji bagaimana analisis usaha VCO dan berapa nilai tambah yang diperoleh petani. Berdasarkan latar belakang tersebut maka tujuan penelitian ini adalah untuk mengetahui besarnya keuntungan usaha pengolahan VCO, efisiensi usaha pengolahan VCO dan besarnya nilai tambah usaha pengolahan VCO. Penelitian ini diharapkan bermanfaat memberikan informasi kepada petani mengenai usaha pengolahan VCO.

\section{METODOLOGI PENELITIAN 2.1. Lokasi dan Waktu Penelitian}

Penelitian ini dilakukan di Kecamatan Enok Kabupaten Indragiri Hilir. Pemilihan lokasi ini dilakukan secara sengaja (purposive) dengan pertimbangan lokasi tersebut merupakan wilayah yang banyak melakukan usaha pembuatan VCO. Penelitian ini dilakukan pada bulan April sampai Juli 2019.

\subsection{Metode Pengambilan Sampel}

Pengambilan sampel secara tidak acak melalui teknik purposive sampling yaitu penarikan sampel yang dilakukan berdasarkan tujuan tertentu dari peneliti. Pemilihan dilakukan dengan alasan sampel dapat mewakili usaha pengolahan VCO dan memiliki wewenang serta pengetahuan yang dibutuhkan untuk memenuhi kebutuhan penelitian. 


\subsection{Metode Analisis Data}

\subsubsection{Analisis Biaya}

Biaya total menurut Wahyu (2010) berarti seluruh biaya yang dikeluarkan oleh suatu perusahaan dalam memproduksi sejumlah output.Sedangkan menurut Samuelson dan Nordhaus (2003) Biaya Total merupakan pengeluaran terendah yang diperlukan untuk memproduksi setiap tingkat output. Biaya Total dihitung dengan menggunakan rumus sebagai berikut:

$$
\mathrm{TC}=\mathrm{TFC}+\mathrm{TVC}
$$

Keterangan:

TC : Biaya Total Usaha (Rp/Produksi)

TFC : Biaya Tetap Usaha (Rp/Produksi)

TVC : Biaya Variabel Usaha (Rp/Produksi)

\subsubsection{Analisis Penerimaan}

Penerimaan adalah perkalian antara produksi yang dihasilkan dengan harga jual dan biasanya produksi berhubungan negatif dengan harga, artinya harga akan turun ketika produksi berlebihan (Soekartawi, 1995). Penerimaan dapat dihitung dengan menggunakan rumus sebagai berikut :

$$
\mathrm{TR}=\mathrm{Q} \times \mathrm{P}
$$

Keterangan :

TR : Penerimaan total (Rp/Produksi)

$\mathrm{Q} \quad$ : Jumlah produk (Rp/Produksi)

$\mathrm{P} \quad$ : Harga produk (Rp/Produksi)

\subsubsection{Keuntungan}

Keuntungan adalah selisish penerimaan total dengan biaya total, secara matematis dirumuskan sebagi berikut :

$$
\pi=\mathrm{TR}-\mathrm{TC}
$$

Keterangan :

$\pi \quad=$ keuntungan (Rupiah)

TR = penerimaan (Rupiah)

$\mathrm{TC}=$ biaya total (Rupiah)

\subsubsection{Efisiensi}

Menurut Soekartawi (1995), analisis

Return Cost (R/C) ratio merupakan perbandingan (ratio atau nisbah) antara penerimaan (revenue) dan biaya (cost). yang dikeluarkan dalam satu kali produksi. Untuk mengetahui efisiensi, maka rumus yang dipakai yaitu:

$$
\text { Efisiensi }=\text { TR/TC }
$$

Keterangan :

$\mathrm{TR}=$ Penerimaan total usaha dagang (Rp/Bulan)

$\mathrm{TC}=$ Total biaya yang dikeluarkan (Rp/Bulan)

Kriteria yang digunakan dalam penilaian efisiensi usaha adalah :

TR/TC Ratio > 1, Usaha dinyatakan layak.

TR/TC Ratio $=1$, Usaha dinyatakan berada pada titik impas.

TR/TC Ratio < 1, Usaha dinyatakan tidak layak.

\subsubsection{Analisis Nilai Tambah}

Nilai tambah diperoleh dari marjin nilai produksi dengan biaya bahan baku dan biaya bahan penolong. Perhitungan nilai tambah digunakan metode hayami (Hayami, 1987). Prinsip metode Hayami adalah menghitung nilai tambah ber unit produk. Metode Hayami lebih sesuai digunakan pada pengukuran nilai tambah produk industri atau agroindustri, kurang tepat jika digunakan untuk usahatani ataupun usaha perdagangan dan jasa. Kelebihan dari Metode Hayami adalah memiliki ragam analisis diantaranya aktor konversi, koefisien tenaga kerja, ratio nilai tambah, pangsa tenaga kerja, tingkat keuntungan, dan marjin. Kelemahannya adalah sulit diterapkan apabila komponen jenis bahan bakunya banyak, jenis bahan penolongnya banyak (Tajidan, dkk., 2019). 


\section{HASIL DAN PEMBAHASAN \\ 3.1. Analisis Usaha}

\subsubsection{Analisis Biaya}

Pada usaha pengolahan VCO, biaya tidak tetap terdiri dari biaya bahan baku, bahan penolong dan biaya tenaga kerja. Biaya tetap yang dihitung adalah biaya penyusutan alat yang digunakan selama proses produksi. Rincian biaya produksi dalam usaha pengolahan VCO dapat dilihat pada Tabel 1.

Berdasarkan Tabel 1, total biaya produksi yang dikeluarkan sebesar Rp.
51.480,00. Biaya tersebut terdiri dari biaya tidak tetap dan biaya tetap. Biaya tidak tetap adalah biaya yang berubah - ubah tergantung dari besar kecilnya produksi yang dihasilkan (Soekartawi, 1995). Biaya tidak tetap dari usaha pengolahan VCO terdiri dari biaya bahan baku yaitu kelapa butiran sebesar Rp. 14.000,00. Bahan penolong terdiri dari botol kemasan dan kapas. Biaya tenaga kerja sebesar Rp. 30.000,00. Ratarata tenaga kerja berjumlah 1 orang. Produksi dilakukan setiap 2 hari sekali.

Tabel 1. Analisis Biaya Produksi Usaha Pengolahan VCO Per Produksi

\begin{tabular}{|c|c|c|c|c|}
\hline No. & Biaya & Satuan & Harga (Rp) & Jumlah (Rp) \\
\hline \multirow[t]{5}{*}{1.} & $\begin{array}{l}\text { Biaya Tidak Tetap } \\
\text { a. Bahan Baku } \\
\text { b. Bahan Penolong }\end{array}$ & buah & 700 & $14.000,00$ \\
\hline & Botol kemasan & Liter & & $4.000,00$ \\
\hline & Kapas & Gram & & $3.000,00$ \\
\hline & c. Tenaga Kerja & $\mathrm{Rp}$ & & $30.000,00$ \\
\hline & Jumlah & & & $51.000,00$ \\
\hline \multirow[t]{4}{*}{2.} & Biaya Biaya Tetap & & & \\
\hline & Penyusutan Alat & $\mathrm{Rp}$ & & 480,00 \\
\hline & Jumlah & & & 480,00 \\
\hline & Total Biaya & & & 51.480 .00 \\
\hline
\end{tabular}

Sumber : Data primer diolah, 2019

Biaya tetap adalah biaya yang jumlahnya tetap, tidak dipengaruhi oleh jumlah produksi (Soekartawi, 1995). Pada Tabel 1, biaya tetap adalah biaya penyusutan alat sebesar Rp. 480,00. Biaya penyusutan ini dihitung dari masing - masing peralatan yang digunakan selama proses produksi. Alat-alat yang digunakan dalam pengolahan arang yang terdiri dari toples, corong, selang, baskom, saringan, parang, pencungkil kelapa, parutan dan sendok pengaduk .

\subsubsection{Penerimaan}

Penerimaan yang diterima oleh pengusaha $\mathrm{VCO}$ adalah perkalian antara jumlah produksi VCO yang dihasilkan dengan harga VCO. Komposisi penerimaaan, keuntungan dan efesiensi usaha pengolahan VCO dapat dilihat pada tabel 2. 
Tabel 2. Komposisi penerimaan, keuntungan dan efisiensi usaha pengolahan VCO per produksi

\begin{tabular}{clcr}
\hline No. & \multicolumn{1}{c}{ Uraian } & Satuan & Jumlah (Rp) \\
\hline 1. & Produksi & $\mathrm{Kg}$ & 1 \\
2. & Harga Jual & $\mathrm{Rp}$ & $120.000,00$ \\
3. & Penerimaan & $\mathrm{Rp}$ & $120.000,00$ \\
4. & Biaya Produksi & $\mathrm{Rp}$ & $51.480,00$ \\
5. & Keuntungan $(3-4)$ & $\mathrm{Rp}$ & $68.520,00$ \\
6. & Efisiensi $(3: 4)$ & $\mathrm{Rp}$ & 2,33 \\
\hline
\end{tabular}

Sumber : Data Primer diolah, 2019

Penerimaan yang diterima oleh pengusaha $\mathrm{VCO}$ adalah perkalian antara jumlah produksi VCO yang dihasilkan dengan harga VCO. Tabel menunjukan bahwa penerimaan yang diperoleh yaitu rata- rata sebesar Rp. 120.000,00 per produksi. Penerimaan diperoleh dari harga VCO rata- rata Rp.120.000,00/kg dikalikan dengan jumlah produksi VCO rata-rata yaitu $1 \mathrm{~kg}$ per produksi.

\subsubsection{Keuntungan}

Keuntungan yang diperoleh usaha pengolahan VCO merupakan selisih antara total penerimaan dengan total biaya yang dikeluarkan. Keuntungan pada usaha pengolahan VCO yang diperoleh sebesar Rp. 68.520,00 per produksi. Produksi dilakukan 2 hari sekali.

\subsubsection{Efisiensi}

Efisiensi usahatani merupakan gambaran layak tidaknya usaha tersebut dilakukan atau diusahakan. $\mathrm{R} / \mathrm{C}$ rasio merupakan perbandingan antara penerimaan kotor (hasil penjualan) dengan biaya total yang dikeluarkan. Salah satu ukuran efisiensi adalah penerimaan untuk rupiah yang dikeluarkan. Dari tabel 2 dapat dilihat bahwa usaha pengolahan VCO layak untuk diusahakan karena nilai RCR yang diperoleh lebih dari satu yaitu 2,33. Nilai ini berarti setiap Rp. 1,00 biaya yang dikeluarkan akan menghasilkan pengembalian sebesar Rp. 2,33. Hasil ini senada dengan penelitian Hartati dan Mulyani (2009). Hasil penelitian tersebut menunjukkan bahwa usaha agroindustri VCO mempunyai prospek baik. Nilai R/C ratio yang lebih besar dari 1 menunjukkan bahwa usaha VCO yang dilakukan oleh pengrajin yang ada di Kabupaten Cilacap sudah efisien dan layak untuk diusahakan.

\subsection{Nilai Tambah}

Analisis nilai tambah berguna untuk mengetahui berapa tambahan nilai yang terdapat pada suatu output yang dihasilkan. Nilai tambah didapat dari besarnya nilai akhir dari produksi dikurangi dengan besarnya nilai bahan baku dan sumbangan input lain. Nilai tambah usaha pengolahan VCO dapat dilihat pada Tabel 3.

Berdasarkan Tabel 3, produksi VCO rata-rata dalam satu kali produksi adalah $1 \mathrm{~kg}$. Untuk menghasilkan produk tersebut diperlukan bahan baku kelapa sebanyak $10 \mathrm{~kg}$. Dengan demikian konversi untuk VCO adalah 
0,1 yang artinya dari $100 \mathrm{~kg}$ kelapa akan dihasilkan $10 \mathrm{~kg}$ VCO. Jumlah tenaga kerja yang digunakan adalah 1 orang. Angka koefisien tenaga kerja yang diperoleh adalah 0,1 .

Produksi VCO bernilai Rp.12.000,00 per $\mathrm{kg}$ bahan baku (diperoleh dari hasil kali antara faktor konversi dengan harga VCO). Nilai tambah yang diperoleh dari pengolahan $1 \mathrm{~kg}$ bahan baku kelapa adalah $\mathrm{Rp}$. 3.500,00. Nilai tambah ini diperoleh dari pengurangan nilai produk dengan harga bahan baku dan nilai input lain. Rasio nilai tambah yang diperoleh adalah sebesar 20,83 \%. Hasil ini senada dengan penelitian Musriyadi dkk (2006) yang menganalisis nilai tambah dan kemampulabaan tiga agroindustri VCO di Kota Bengkulu. Hasilnya adalah nilai tambah VCO sebesar Rp $3.341,00 /$ butir.

Imbalan tenaga kerja diperoleh dari hasil kali antara koefisien tenaga kerja dengan upah tenaga kerja. Jadi, pendapatan tenaga kerja dari setiap butir kelapa yang diolahnya yaitu Rp. $3.000,00$ per $\mathrm{kg}$. Persentase imbalan tenaga kerja terhadap nilai tambahnya adalah 29,17 \%. Imbalan terhadap modal dan keuntungan diperoleh dari nilai tambah dikurangi besar imbalan tenaga kerja. Keuntungan dari pengolahan VCO adalah sebesar Rp.500 per kg dengan tingkat keuntungan 14,29 $\%$. Hasil ini senada dengan penelitian Hartati dan Mulyani (2009) yang berjudul profil dan prospek bisnis minyak dara (Virgin Coconut Oil/VCO) di Kabupaten Cilacap. Hasil penelitian tersebut menunjukkan keuntungan agroindustri VCO sebesar Rp.517,62 per $\mathrm{kg}$ dengan tingkat keuntungan $25,88 \%$.

\section{KESIMPULAN DAN SARAN}

\subsection{Kesimpulan}

Penerimaan dari usaha pengolahan VCO di Kecamatan Enok adalah sebesar Rp. 120.000,00 per produksi. Total biaya yang harus dikeluarkan untuk satu kali produksi sebesar Rp.51.480,00, sehingga keuntungan usaha adalah Rp. 68.520,00 per produksi. Berdasarkan analisis R/C diperoleh efisiensi usaha sebesar 2,33. Dari hasil ini usaha pengolahan VCO layak untuk diusahakan. Setiap Rp. 1,00 biaya yang dikeluarkan untuk pengolahan VCO akan menghasilkan pengembalian sebesar Rp. 2,33. Berdasarkan perhitungan dengan metode Hayami, nilai tambah yang diperoleh dari pengolahan $1 \mathrm{~kg}$ bahan baku kelapa adalah Rp. 3.500,00. Rasio nilai tambah yang diperoleh adalah sebesar 20,83 \%. Keuntungan dari pengolahan VCO adalah sebesar Rp.500 per kg dengan tingkat keuntungan 14,29 $\%$.

\subsection{Saran}

Petani pengolah VCO diharapakan dapat melakukan kemitraan dengan pemerintah untuk meningkatkan kapasitas produksi dan menambah pangsa pasar agar keuntungan usaha dapat meningkat. Selain itu, petani juga diharapkan dapat meningkatkan kualitas produk agar memperoleh harga jual yang lebih tinggi.

\section{DAFTAR PUSTAKA}

Badan Pusat Statistik Provinsi Riau. 2013. Data Perkebunan Indragiri Hilir. Badan Pusat statistik Provinsi Riau, Pekanbaru. 
Dinas Koperasi dan UKM Kabupaten Indragiri Hilir. 2017. UKM dalam Bidang Kelapa. Laporan Tahunan UKM Kab. Inhil. Dinas Koperasi dan UKM Kabupaten Indragiri Hilir, Tembilahan.

Hayami, Y. et al. 1987. Agricultural marketing and processing in upland Java. A perspective from a Sunda village. CGPRT Centre. Bogor.

Hartanti dan Mulyadi. 2009. Profil dan Prospek Bisnis minyak Dara (Vigin Coconut Oil/VCO) Di Kabupaten Cilacap. Jurnal Agroland. 16(2): 130-140.
Tajidan, Halil, Efendi, Fernandes. 2019. Nilai Tambah VCO Pada Unit Bisnis Agroindustri "Andana" Di kabupaten Lombok Utara. Jurnal Gema Ngabdi. 1(3): 92102.

Musriyadi Nabiu, Ellys Yuliarti, Esteria Manurung. 2006. Analisis nilai Tambah dan Kemampulabaan Tiga agroindustri $\mathrm{VCO}$ di Kota Bengkulu. Jurnal Agrisep. 4(1): 53-62.

Samuolson.P.A dan

W.D.Nordhaus.2003. Ilmu

Mikro ekonomi. PT. Media Global Edukasi. Jakarta.

Soekartawi. 1995. Analisis Usaha Tani, UI Press.

Jakarta 